\title{
Kinetics of the bronchoalveolar leucocyte response in rats during exposure to equal airborne mass concentrations of quartz, chrysotile asbestos, or titanium dioxide
}

\author{
K DONALDSON, R E BOLTON, A JONES, G M BROWN, M D ROBERTSON, \\ J SLIGHT, H COWIE, J M G DAVIS \\ From the Institute of Occupational Medicine, Edinburgh
}

ABSTRACT The kinetics of the bronchoalveolar response was assessed in rats exposed, at equal airborne mass concentration $\left(10 \mathrm{mg} / \mathrm{m}^{3}\right)$, to titanium dioxide - a non-pathogenic dust - and the two pathogenic mineral dusts quartz and chrysotile asbestos. Rats were killed at intervals over a 75 day exposure period and groups of rats exposed for 32 and 75 days after recovery for two months. Bronchoalveolar lavage was carried out and the lavage fluid characterised for cellular content, macrophage activation, and concentrations of free total protein, lactate dehydrogenase, and $N$ acetyl- $\beta$-D-glucosaminidase. Inhalation exposure to the two pathogenic dusts resulted in an increased number of leucocytes, macrophage activation, and increased levels of free enzymes and total protein. The pattern and magnitude of the responses to quartz and chrysotile differed. Chrysotile caused less inflammation than quartz, and the main cellular response peaked around the middle of the period of dust exposure whereas the highest levels of enzymes occurred towards the end. The difference in timing suggests that macrophages were not available for lavage towards the end of the exposure, owing to their playing a part possibly in deposition of granulation tissue. Quartz caused a greater cellular and enzyme response than chrysotile, particularly towards the end of the dust exposure phase. There was a noticeable progression of inflammation in the quartz exposed groups left to recover for two months, but not in the chrysotile recovery groups.

\section{Introduction}

Prolonged inhalation of asbestos dust may lead to the development of asbestosis (a form of interstitial lung fibrosis), bronchogenic carcinoma, and (with some types of asbestos) mesothelioma. ${ }^{\prime}$ Exposure to quartz produces the fibrotic lung disease silicosis, in which the primary lesion is nodular in contrast to that in asbestosis. ${ }^{2}$ Many studies have used bronchoalveolar lavage to examine the pulmonary response in people occupationally exposed to pathogenic dusts ${ }^{3-6}$ and in experimentally exposed animals. ${ }^{78}$

Bronchoalveolar lavage has been used in many other pulmonary diseases for diagnosis and staging ${ }^{9}$ and in the attempt to elucidate the cellular events underlying the pathological changes. ${ }^{10}$ Such studies have centred on the leucocytes in bronchoalveolat.

Address for reprint requests: $\operatorname{Dr} \mathrm{K}$ Donaldson, Institute of Occupational Medicine, Edinburgh EH8 9SU.

Accepted 27 April 1988 lavage fluid in view of their prevalence and their key role in inflammation, the immune response, carcinogenesis, and control of mesenchymal cell proliferation. These studies show that the quantity and function of the bronchoalveolar leucocytes may determine current state of disease and subsequent progression. ${ }^{910} \mathrm{We}$ attempted to define differences in the bronchoalveolar leucocyte response to equal airborne mass concentrations $\left(10 \mathrm{mg} / \mathrm{m}^{3}\right)$ of three dusts of very different pathogenic potential: titanium dioxide, a nonfibrogenic dust commonly used in mineral dust studies as an inert control;" chrysotile asbestos, which causes diffuse interstitial lung fibrosis and is a pulmonary carcinogen; and quartz, which causes nodular pulmonary fibrosis.

\section{Methods}

ANIMALS

Male specific pathogen free rats of the $P V G$ strain, 
inbred at the institute's animal unit, were used; they were 12 weeks old at the start of dust exposure.

\section{DUSTS}

The dusts used were titanium dioxide $\left(\mathrm{TiO}_{2}\right)$ (rutileTioxide UK Ltd, Stockton on Tees), quartz (Sikron F600, Eurostandard), and chrysotile asbestos (Union Internationale Contre Cancer (UICC) standard sample "A").

\section{GENERATION AND MEASUREMENT OF DUST CLOUDS}

Groups of up to 48 rats were exposed to dust clouds of $10 \mathrm{mg} / \mathrm{m}^{3}$ in $1 \mathrm{~m}^{3}$ inhalation chambers. ${ }^{12}$ The dusts were dispersed into the chambers with Wright dust dispensers $^{13}$ for the two non-fibrous dusts and a Timbrell fibrous dust dispenser ${ }^{14}$ was used for chrysotile asbestos. The rats were exposed for seven hours a day, five days a week, over a maximum period of 15 weeks ( 75 days' exposure). The mass concentration of respirable dust was measured daily in each chamber with the Casella MRE 113A sampler. The present legal factory limit for quartz is $0.1 \mathrm{mg} / \mathrm{m}^{3}$, although this may be exceeded in exposure to mixed dusts, where there may be no legal limit. The present legal limit for chrysotile asbestos is $0 \cdot 1 \mathrm{fibre} / \mathrm{ml}$ and UICC chrysotile at $10 \mathrm{mg} / \mathrm{m}^{3}$ produces about 2000 fibres $/ \mathrm{ml}$. The inert dust titanium dioxide has no specified legal limit.

\section{PROTOCOL}

Groups of four rats were removed from the chamber and killed for study after $2,4,8,16,32,52$, and 75 days' exposure. In addition, groups of four rats were removed from exposure after 32 and 75 days and kept for 62 days before being killed. These latter groups were designated as $\mathbf{3 2}$ days or $\mathbf{7 5}$ days plus recovery. On each experimental day two control rats, similar in age to the experimental rats, were killed and studied in an identical manner.

\section{BRONCHOALVEOLAR LAVAGE}

Rats were killed by intraperitoneal injection of pentobarbitone sodium (Ceva, Watford) and weighed. The lungs were exposed by dissection and exsanguinated while in situ by injecting $30 \mathrm{ml}$ of $0.85 \%$ sodium chloride $\left(37^{\circ} \mathrm{C}\right)$ slowly through the right ventricle; blanching of the lungs indicated exsanguination. To prevent flow back due to hydrostatic pressure in the pulmonary vasculature, the right auricle was cut before injection of the final $5 \mathrm{ml}$. The trachea was cannulated with a blunt 16 gauge needle secured with nylon thread. The lungs, heart, and trachea were removed en bloc, weighed, and suspended in $0.85 \%$ $\mathrm{NaCl}$ at $37^{\circ} \mathrm{C}$ until they were lavaged. The lungs were placed on a cork mat and $4 \times 10 \mathrm{ml}$ aliquots of $0.85 \%$ $\mathrm{NaCl}$ at $37^{\circ} \mathrm{C}$ were introduced into the lungs and then gently withdrawn before the next aliquot. After instillation of the first $5 \mathrm{ml}$ of the second lavage the lungs were massaged by gently stroking them outwards towards the tip of each lobe; the remaining $5 \mathrm{ml}$ was then instilled and removed in the usual way; this procedure increases the yield of cells. ${ }^{15}$ Each $10 \mathrm{ml}$ of lavage fluid was stored separately in ice cold plastic tubes to allow the soluble elements in the first $10 \mathrm{ml}$ of fluid to be analysed separately without excessive dilution. The heart, the mediastinal lymphoid and adipose tissue, and the trachea plus the cannula were dissected free of the lung and weighed; this weight was subtracted from the initial total weight to give the weight of lung tissue. The lung:body weight ratio (lung index) was calculated for each rat.

\section{DETER MINATION OF CELL NUMBERS}

Cells were obtained from the pooled $40 \mathrm{ml}$ of lavage fluid by centrifugation, and counted in a Neubauer chamber after dilution. Cytocentrifuge (Shandon, Runcorn) preparations were made and stained with May-Grünwald-Giemsa stain, and a differential count was performed. The proportions of the following cell types were determined and converted to absolute cell counts: macrophages, neutrophils, lymphocytes, monocytes, binucleate macrophages, and multinucleate macrophages.

\section{DETERMINATION OF SOLUBLE ELEMENTS}

The concentrations of the following proteins in the first $10 \mathrm{ml}$ of lavage fluid were assessed as described: total protein by the Coomassie Blue method (BioRad, Bradford), the cytoplasmic enzyme lactate dehydrogenase, ${ }^{16}$ and the lysosomal enzyme $N$-acetyl$\beta$-D-glucosaminidase. ${ }^{17}$

\section{ASSA YS OF MACROPHAGE ACTIVITY}

Phagocytosis was assessed on days 8,32 , and 75 . Triplicate coverslip cultures of macrophages were prepared by incubation of $100 \mu \mathrm{l}$ of lavaged cells $\left(10^{6}\right.$ cells $/ \mathrm{ml}$ of $\mathrm{F} 10$ medium and $10 \%$ heat inactivated fetal calf serum (complete medium)) on $6 \times 22 \mathrm{~mm}$ alcohol cleaned glass coverslips (Chance-Propper, Warley) for one hour at $37^{\circ} \mathrm{C}$ in a humidified $5 \%$ carbon dioxide atmosphere. Coverslips were then washed vigorously in saline to remove non-adherent cells and placed on racks. Fluoresceinated latex beads (Polysciences, Warrington) were diluted 1:40 with complete medium and incubated for one hour at $37^{\circ} \mathrm{C}$, and $100 \mu \mathrm{l}$ was added to each coverslip culture. After 1.5 hours the coverslips were washed in four changes of saline to remove non-attached beads before being fixed in methanol for five minutes and mounted in phosphate buffered saline and glycerol (1:1). One hundred random cells were counted on each coverslip and scored as phagocytic if seen to contain three or more latex beads when viewed in an ultraviolet microscope with a $\times \mathbf{4 0}$ objective. 
Macrophage spreading was assessed by preparing macrophages on coverslips in complete medium at $10^{6} / \mathrm{ml}$ as described above and incubating the coverslips for one hour at $37^{\circ} \mathrm{C}$ in a humidified $5 \%$ carbon dioxide atmosphere to allow adherence and spreading. The coverslips were fixed for five minutes in methanol and then stained with Diff-Quik. The mean diameter of 200 macrophages was assessed with a microscope interfaced with a digitising computer. ${ }^{18}$ Occasional adherent neutrophils were clearly distinguishable from macrophages and were not measured.

\section{HISTOLOGY}

Lungs lavaged in the latter part of each exposure regimen were fixed in formalin processed to paraffin wax, and sections stained with haematoxylin and eosin.

\section{ANALYSIS OF RESULTS}

Results were obtained from four experimental rats and two control rats on each day. The initial assessment of the control data showed the anticipated day to day variation but no significant difference from $\mathrm{TiO}_{2}$ exposed rats; in the case of spreading, macrophages from $\mathrm{TiO}_{2}$ exposed rats showed a $0 \cdot 5-1 \mu \mathrm{m}$ increase over control macrophages, which was not significant. All data were logarithmically transformed, values from exposed animals were corrected by subtracting control values on that day to obtain a "standardised" figure, equivalent to the ratio dust exposed:control, for each rat for each assay. This figure was used to compare $\mathrm{TiO}_{2}$ exposed rats with rats exposed to the pathogenic mineral dusts by means of analysis of variance with the Genstat computer statistical package. Where differences were seen in the analysis of variance, paired comparisons using a $t$ test were made at each time point between the three groups and values of $p<0.01$ were taken to indicate a significant difference. For a variable for which seven time points are used this is equivalent to $p<0.07$ overall, and for a variable where nine time points are used to $p<0.09$. No data were available for $\mathrm{TiO}_{2}$ exposed rats on days 4 and 8 .

\section{Results}

DUST EXPOSURE TARGETS

The airborne concentrations of each dust for each day were within $\pm 30 \%$ of the target mean concentration in 212 out of 225 results. At the end of 75 days of dust exposure the mean daily dust concentrations in each chamber were: titanium dioxide $9.9 \mathrm{mg} / \mathrm{m}^{3}$, chrysotile $10 \cdot 0 \mathrm{mg} / \mathrm{m}^{3}$, and quartz $10 \cdot 1 \mathrm{mg} / \mathrm{m}^{3}$.

\section{MACROPHAGE NUMBERS}

The predominant cell types in lavage fluid were macrophages in control rats and macrophages plus

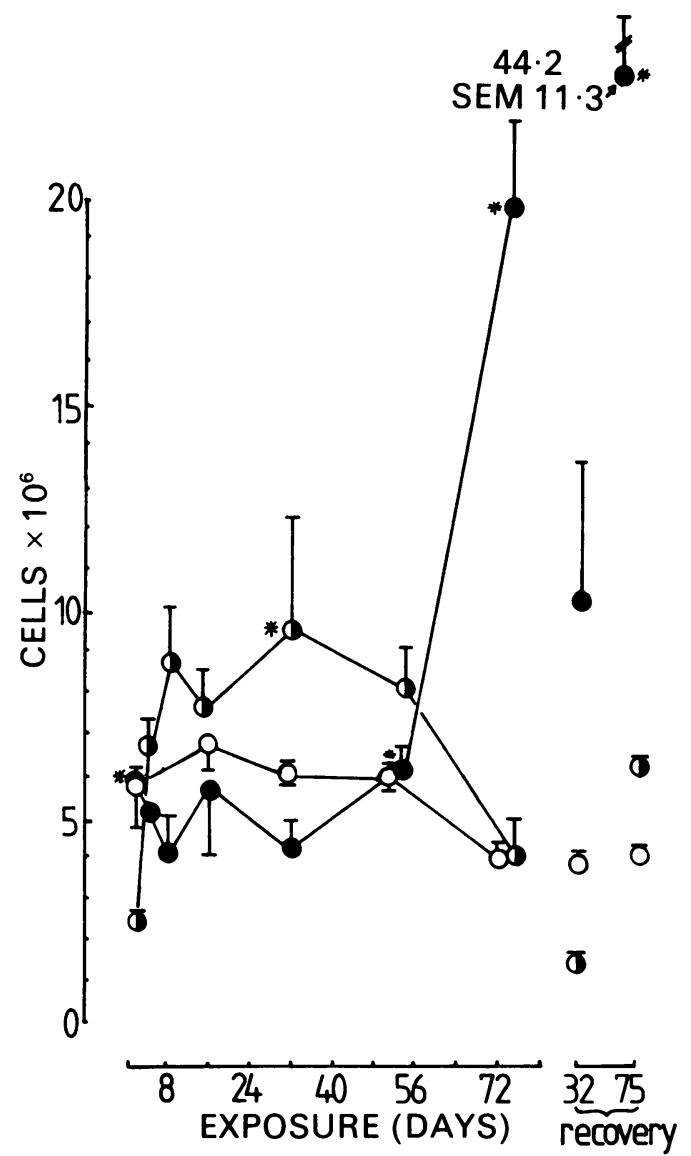

Fig I Numbers of macrophages lavaged from the lungs of rats exposed to airborne titanium oxide $\left(\mathrm{TiO}_{2}\right)$, quartz, or chrysotile asbestos (means with standard errors). An asterisk denotes a significant $\left(p<0.01\right.$ ) difference from the $\mathrm{TiO}_{2}$ exposed group. $\mathrm{O}-\mathrm{O} \mathrm{TiO}_{2} ; 0-0$ quartz; $0-0$ chrysotile.

neutrophils in rats exposed to quartz and chrysotile. Basophils and eosinophils never exceeded $1 \%$ and lymphocytes never exceeded $10 \%$ of the total cells. With chrysotile macrophages were twice as numerous as in control samples by day 32 (fig 1) but had returned to control levels by 75 days. With quartz macrophage numbers remained at around control levels initially but then increased fourfold between days 52 and 75 . In rats treated with titanium dioxide, macrophage numbers remained at control levels throughout the period of dust exposure. Rats treated with quartz for 32 or 75 days and allowed to recover showed an increase in macrophage numbers during the recovery period. With animals exposed for 75 days and examined two months later, macrophage numbers were 10 times higher than in control animals. Animals exposed to 


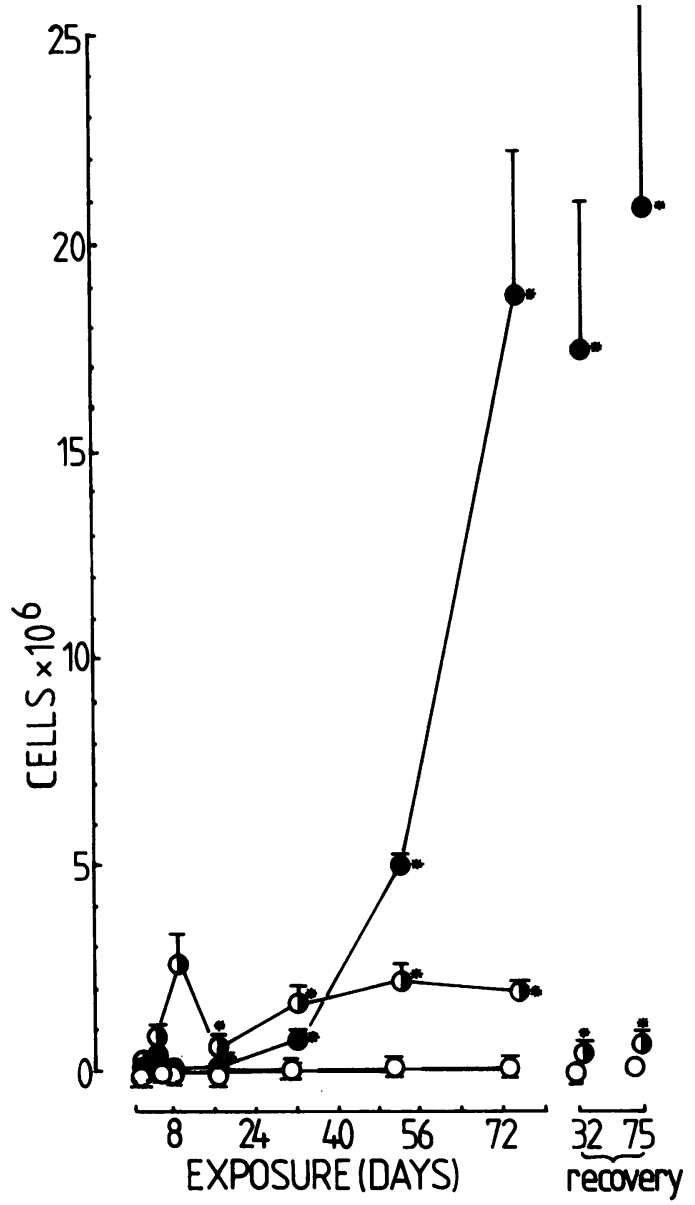

Fig 2 Numbers of neutrophils lavaged from the lungs of rats exposed to airborne titanium oxide ( $\mathrm{TiO}_{2}$ ), quartz, or chrysotile asbestos (means with standard errors). An asterisk denotes a significant $(p<0.01)$ difference from the $\mathrm{TiO}_{2}$ exposed group. $\mathrm{O}-\mathrm{O} \mathrm{TiO}_{2} ; \mathrm{O}-\mathrm{quartz} ; \mathrm{O}-\mathrm{O}$ chrysotile.

chrysotile showed no increase in macrophages during recovery periods.

In the untreated and $\mathrm{TiO}_{2}$ treated rats the number of mononuclear cells identified morphologically as monocytes never exceeded $0 \cdot 1 \times 10^{6}$ cells/rat and was frequently zero. With chrysotile exposure the mean (SEM) number of monocytes was significantly greater than with $\mathrm{TiO}_{2}$ exposure on days 32 and $52(0 \cdot 15(0 \cdot 07)$ and $0.25(0.08) \times 10^{6}$ respectively). With quartz exposure a rise in monocytes did not occur until 75 days $\left(0.23(0.22) \times 10^{6}\right)$ but, by contrast with chrysotile exposure, this persisted in both the 32 and 75 day recovery animals $(0.39(0.12)$ and $0.35(0.45)$ $\left.\times 10^{6}\right)$.

The number of binucleate macrophages was extremely low in the untreated and $\mathrm{TiO}_{2}$ exposed rats $\left(<0.32 \times 10^{6}\right)$. The numbers were significantly higher in chrysotile exposed rats from day 16 to day 75 and during recovery (range $0.39-0.83 \times 10^{6}$ ). With quartz there was also an increase in the number of binucleate cells but not until day $75\left(0.41(0.12) \times 10^{6}\right)$; the numbers were particularly high in the 75 day recovery group $\left(1.58(1.05) \times 10^{6}\right)$.

Multinucleate macrophages were absent or very few in the untreated and $\mathrm{TiO}_{2}$ exposed groups (range $\left.0-0.02 \times 10^{6}\right)$. The numbers were significantly increased in the later two thirds of the chrysotile exposure period (range $0 \cdot 12-0.29 \times 10^{6}$ ) and on day 75 with quartz exposure $\left(1.69(0.77) \times 10^{6}\right)$. Macrophages showing mitosis were rare in both the control and the pathogenic dust exposed groups (range 0-0.04 $\left.\times 10^{6}\right)$; only with 75 day quartz exposure was there a significant increase over $\mathrm{TiO}_{2}\left(0.05(0.08) \times 10^{6}\right)$, and this was not maintained in the 75 day recovery group.

\section{NEUTROPHIL NUMBERS}

No neutrophils were present in lavage fluid from untreated or $\mathrm{TiO}_{2}$ exposed rats at any time (fig 2). Exposure to both chrysotile and quartz resulted in significant increases in numbers of neutrophils by comparison with $\mathrm{TiO}_{2}$ from 16 days onwards, much larger numbers being seen with quartz. On days 52 and 75 with quartz the numbers of neutrophils were $5 \cdot 1$ and $18.8 \times 10^{6}$. The number of of neutrophils was greater in the 32 days plus recovery group $\left(17.6 \times 10^{6}\right)$ than in the 32 day group $\left(0.8 \times 10^{6}\right)$. With chrysotile neutrophil numbers never exceeded $3 \times 10^{6}$ and in the latter two thirds of the exposure mean values remained at 1-2 $\times 10^{6}$ cells per rat. In the chrysotile recovery groups neutrophil numbers were greater than in the $\mathrm{TiO}_{2}$ controls but (by contrast with the quartz group) smaller than in the equivalent treatment groups that had not been allowed to recover.

\section{LYMPHOCYTE NUMBERS}

Lymphocyte numbers were low, though the percentage was greater in the chrysotile exposed rats (mean $8.4\left(\right.$ SEM 5.5)) than in the quartz $(4.8(2.7))$ or $\mathrm{TiO}_{2}$ exposed $(3 \cdot 8(2 \cdot 6))$ rats.

\section{MACROPHAGE FUNCTION}

The ability of macrophages to spread after culture for $N_{\omega}$ one hour on glass, a marker of macrophage activation, $\vec{C}$ was assessed at all time points (fig 3). Rapid macro- $o$

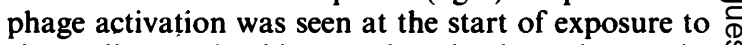
chrysotile, and this continued throughout the $\stackrel{\infty}{+}$ exposure period, although there was an unexpectedly 0 low level of spreading at 75 days. The fact that the 75 day plus recovery cells had spreading similar to that present from day 8 to day 52 suggests that $\stackrel{\mathbb{Q}}{\propto}$ an unidentifiable technical error may have been responsible. With quartz no great increase in spreading 


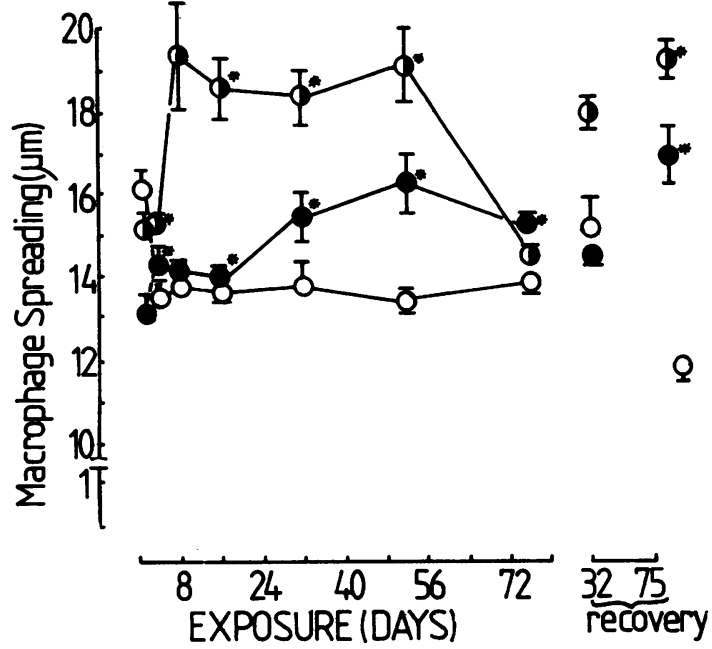

Fig 3 Spreading activity of macrophages lavaged from the lungs of rats exposed to airborne titanium oxide $\left(\mathrm{TiO}_{2}\right)$, quartz, or chrysotile asbestos (means with standard errors). An asterisk denotes a significant $(p<0.01)$ difference from the $\mathrm{TiO}_{2}$ exposed group. $\mathrm{O}-\mathrm{O} \mathrm{TiO}_{2}$; $-\mathrm{quartz}$; -1- chrysotile.

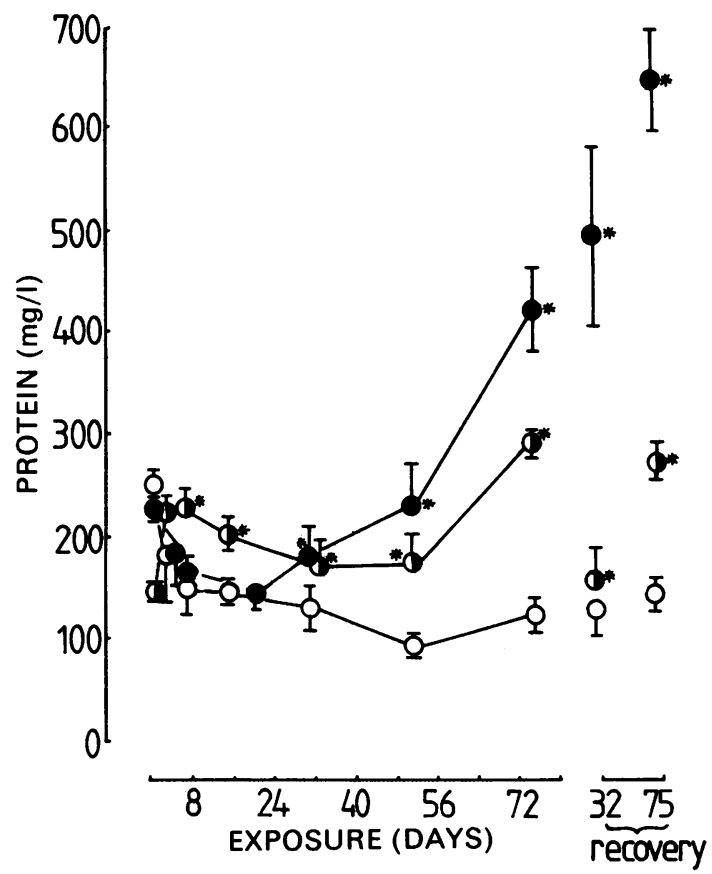

Fig 4 Protein concentrations in the first $10 \mathrm{ml}$ of lavage fluid obtained from rats exposed to airborne titanium oxide $\left(\mathrm{TiO}_{2}\right)$, quartz, or chrysotile asbestos (means with standard errors). An asterisk denotes a significant $(p<0.01)$ difference from the $\mathrm{TiO}_{2}$ exposed group. $\mathrm{O}-\mathrm{O} \mathrm{TiO}_{2}$; - quartz; $1-0$ chrysotile.

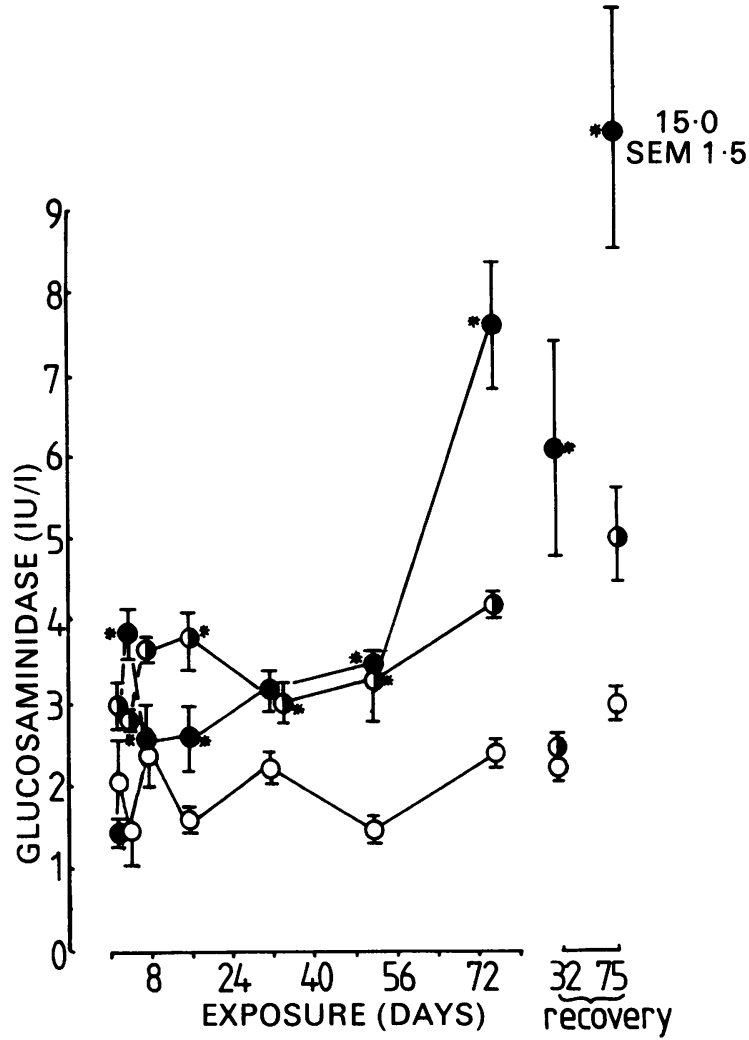

Fig 5 Activity of the lysosomal enzyme $N$-acetyl- $\beta$-Dglucosaminidase in the first $10 \mathrm{ml}$ of lavage fluid obtained from rats exposed to airhorne titanium oxide ( $\left.\mathrm{TiO}_{2}\right)$. quart:. or chrysotile ashestos (means with standard errors). An asterisk denotes a significant $(p<0 \cdot() I)$ difference from the $\mathrm{TiO}_{2}$ exposed group. $\mathrm{O}-\mathrm{O} \mathrm{TiO}_{2}$ : $\bigcirc-\mathrm{quart}_{\mathrm{O}} \mathrm{O}-\mathrm{O}$ chrysotile.

was observable until 32 days, but this macrophage activation was maintained throughout the dust exposure period in the 75 day recovery group, though not in the 32 day recovery group. The proportion of macrophages able to phagocytose fluoresceinated latex beads was constant throughout the exposure regimen, being in the range $89-95 \%$ for all three dusts.

\section{SOLUBLE COMPONENTS}

Protein concentrations in lavage fluid from the control rats were initially high (days 2 and 4 ) for unknown reasons. Subsequent concentrations were around 150 $\mathrm{mg} / \mathrm{ml}$ (fig 4). In the $\mathrm{TiO}_{2}$ exposed groups the level was slightly lower than in the controls throughout most of the exposure period, but both chrysotile and quartz exposure produced significantly more protein in the bronchoalveolar space than $\mathrm{TiO}_{2}$. This effect was evident from eight days with chrysotile and from 32 days with quartz. During both recovery periods after quartz exposure there was a further increase in protein 


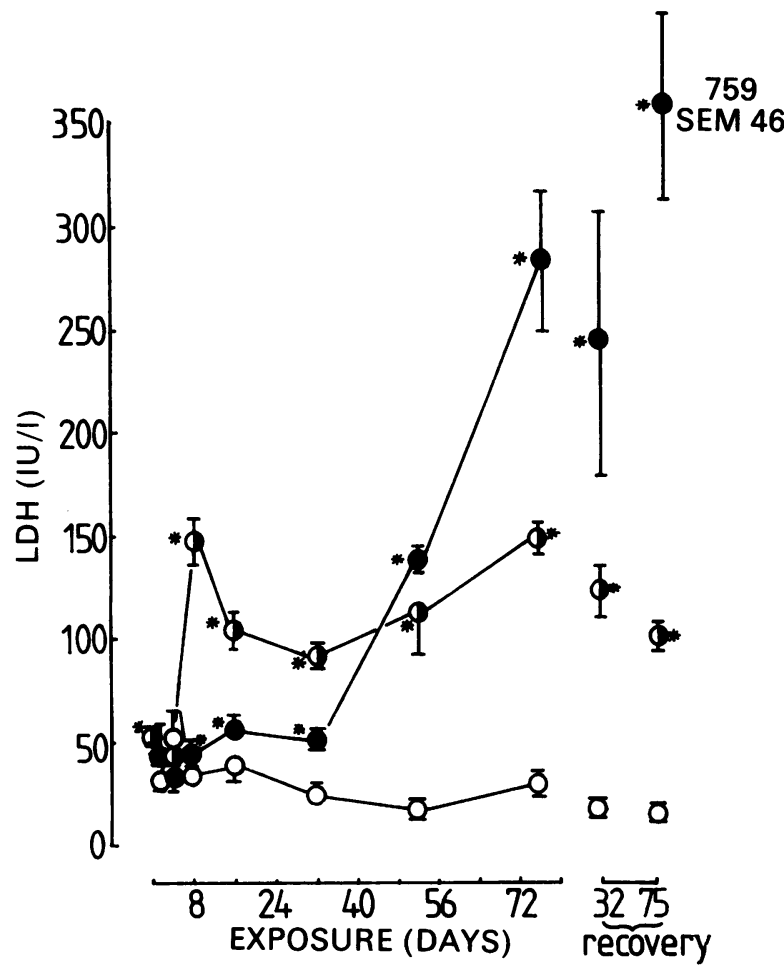

Fig 6 Activity of the cytoplasmic enzyme lactate dehydrogenase (LDH) in the first $10 \mathrm{ml}$ of lavage fluid obtained from rats exposed to airborne titanium oxide $\left(\mathrm{TiO}_{2}\right)$, quartz, or chrysotile asbestos (means with standard errors). An asterisk denotes a significant $(p<0.01)$ difference from the $\mathrm{TiO}_{2}$ exposed group. $\mathrm{O}-\mathrm{O} \mathrm{TiO}_{2}$, - quartz; 0 -O chrysotile.

concentration, particularly in the 32 day exposed animals-from $182 \mathrm{mg} / \mathrm{ml}$ at the end of exposure to $492 \mathrm{mg} / \mathrm{ml}$ after two months of recovery. With chrysotile there was no change in protein concentrations during recovery. The two enzymes measured in the lavage fluid (figs 5 and 6) showed similar patterns, both being unaltered with $\mathrm{TiO}_{2}$ exposure. Chrysotile exposure caused early increases, which were maintained throughout the middle part of the exposure period, and rose further towards the end of exposure. Quartz caused modest early increases, with high levels of free enzyme towards the end of exposure. During recovery the concentrations of both enzymes increased in the quartz groups but with chrysotile the concentrations of enzyme remained the same as at the end of exposure.

\section{LUNG INDEX}

The lung index (lung weight:body weight $\times 10^{4}$ ) gave conflicting results, with some early increases in the chrysotile and quartz exposed groups that did not persist, although there were increases at some of the later time points.

\section{HISTOLOGY}

Diffuse fibrosis of the lungs developed in the chrysotile exposed rats and nodular fibrosis in the quartz exposed rats after prolonged exposure.

\section{Discussion}

In this study rats were exposed to equal airborne respirable mass concentrations $\left(10 \mathrm{mg} / \mathrm{m}^{3}\right)$ of quartz, chrysotile asbestos, and titanium dioxide. Differences were detected in the bronchopulmonary lavage fluid profile between the three dust types in terms of the kinetics of cell accumulation and the presence of soluble factors considered important in inflammation.

Titanium dioxide is an amorphous particulate, which in the rutile form used in the present study is employed in the paint, cosmetic, and food industries. Epidemiologically, $\mathrm{TiO}_{2}$ is largely non-pathogenic in the lungs of occupationally exposed individuals. ${ }^{1920}$ Exposure of laboratory animals to $\mathrm{TiO}_{2}$ also failed to induce a fibrogenic response, ${ }^{1121}$ although pathological changes occurred at a very high dose $(250$ $\mathrm{mg} / \mathrm{ml}){ }^{22}$ In our unpublished studies we have found $\mathrm{TiO}_{2}$ to be only slightly cytotoxic to alveolar macrophages and much less toxic than chrysotile or quartz; it also causes negligible inflammation when injected into the peritoneal cavity of mice ${ }^{23}$ or the lungs of rats. The bronchoalveolar response to medium term exposure to $10 \mathrm{mg} / \mathrm{m}^{3}$ airborne $\mathrm{TiO}_{2}$ in the present study was consistent with its non-reactive nature. Alveolar macrophages phagocytosed the $\mathrm{TiO}_{2}$ extensively, as shown by particle laden macrophages predominating in the lavaged cell population, but there was no increase in lactate dehydrogenase activity suggesting cell death. There was, however, evidence of a degree of macrophage activation in the slight but persistently increased spreading in $\mathrm{TiO}_{2}$ exposed macrophages, but no increase in glucosaminidase was seen in the lavage fluid, which suggested no release of lysosomal enzymes. There was also no evidence of increased mitosis in macrophages or giant cell formation as exposure progressed, and no neutrophil influx to $\mathrm{TiO}_{2}$ exposed lung.

In contrast to this lack of response with $\mathrm{TiO}_{2}$, both chrysotile asbestos and quartz, mineral dusts whose pathogenic potential is well known, caused pulmonary inflammation. The macrophage increases, found predominantly in the middle of the exposure phase with chrysotile asbestos, were modest, as found in other studies exposing animals to asbestos by inhalation, ${ }^{24} 25$ and was not matched by a rise in monocytes, which, although significantly increased in 
number, still formed a very small proportion of the macrophage population.

Phagocytosis of asbestos causes macrophage activation and formation of multinucleate giant cells, a process probably stimulated by the inability of single macrophages to engulf the longer fibres completely. In the chrysotile exposed animals macrophage, multinucleate giant cell, and neutrophil numbers all peaked around the middle of the dust exposure phase and tended to undergo a slight decline towards the end of the exposure regimen. In contrast, the levels of free lactate dehydrogenase, glucosaminidase, and protein were rising towards the end of dust exposure. Rising levels of enzyme release indicate progressive pulmonary inflammation, and one explanation of the contradictory cell and enzyme data is that macrophages that have phagocytosed asbestos tend to be taken up in deposits of granulation tissue around the terminal and respiratory bronchioles, ${ }^{27}$ thus making them unavailable for lavage. Such lesions were evident in sections of asbestos exposed lung. The inflammatory indices taken together, however, show that chrysotile does not produce the extent or progression of inflammation found with quartz.

The sudden peak of lactate dehydrogenase activity, indicative of cell death, from day 4 to day 8 of chrysotile exposure may be related to the concurrent neutrophil influx and could be a result of chrysotile cytotoxicity to macrophages, with release of lactate dehydrogenase and macrophage derived neutrophil chemotactic factor ${ }^{28}$ from dying cells. The lactate dehydrogenase may, however, be derived from alveolar epithelial cells injured by the products of inflammatory leucocytes. ${ }^{29}$ Support for the latter possibility comes from the increased total protein in the lavage fluid, indicating increased permeability at the endothelial-alveolar epithelial barrier.

Rats exposed to quartz for up to 12 days showed no cellular or humoral changes except for low level neutrophil influx, but by 52 days there was a five fold increase over the 32 day level, with an accompanying increase in total protein, suggesting increased permeability of the epithelial barrier, and raised lactate hydrogenase activity, suggesting cell death. This was followed towards the end of the exposure phase by massive macrophage and neutrophil influx with associated increases in free enzyme and protein. As with chrysotile, the increase in macrophage number was not met by substantial increase in mitotic macrophages or monocytes and so presumably was due to emigration of interstitial macrophages into the alveolar space. Macrophages produce a neutrophil chemotactic factor in response to quart $z^{30}$ and this may have induced the large neutrophil influx. There was a concurrent notable increase in free lactate hydrogenase on day 52 , suggesting cell death in the bronchoalveolar region. Macrophage breakdown products have been reported to possess powerful activity in causing inflammatory cell recruitment, ${ }^{31}$ and this could have been a factor causing further accumulation of leucocytes in quartz exposed lung.

The recovery experiments showed that the intensity of the quartz induced alveolitis increased during the two months in which the animals breathed normal air. This progression was particularly noticeable in the 32 day exposed group. With the 75 day exposed group there was also evidence of progression, although this was generally less, perhaps because by 75 days of quartz exposure there was a near maximum response.

It has been suggested that contaminating minerals, including aluminium, may protect against quartz toxicity during exposure to mixed dusts, with progression of disease when this protection is lost at cessation of exposure. ${ }^{32}$ Our data, obtained with a highly pure quartz standard, indicate that contaminating minerals are not a prerequisite for progression of pulmonary inflammation on cessation of exposure to quartz. With chrysotile there was no evidence of progression of inflammation in animals allowed to recover after exposure.

The phagocytic activity of macrophages did not differ between the three dust types, although the assay does not detect the total phagocytic potential of the population, which may have altered, but provides information only on the cells able to phagocytose, which approached $90 \%$ in all cases. The lung weight:body weight ratio indicated significant differences between lungs exposed to $\mathrm{TiO}_{2}$ and to pathogenic dusts; but these were not consistent and we conclude that the method is not sufficiently sensitive.

There was a modest rise in the proportion of lymphocytes in the lavage fluid from the chrysotile exposed rats by comparison with the rats that had the other two treatments. This is in keeping with the increased number of lymphocytes reported in bronchoalveolar lavage fluid from patients with asbestosis ${ }^{3}$ and suggests that some immune phenomenon may be occurring.

The difference in the kinetics of the alveolitis produced by asbestos and by quartz may indicate different responses to the dusts. Chrysotile produces an early response, with an influx of inflammatory cells in as little as eight days; but many of the cells that have phagocytosed dust may become bound up in the lung tissue. Once the inflammatory response to quartz has started, its progression is consistent with the known highly toxic nature of this material. Quartz particles not cleared from the lung retain their toxicity, probably killing generations of macrophages and thus stimulating the recruitment of greater numbers of leucocytes. The lack of enhanced leucocyte response to inhaled quartz during the early phase of dust inhala- 
tion has been reported previously ${ }^{33}$ and in vitro studies may provide an explanation. These have shown that, although quartz is more toxic than chrysotile, both dusts kill most macrophages within 48 hours. ${ }^{34}$ Equal masses of the two dust types would therefore have been expected to produce similar levels of pulmonary inflammation with recruitment of inflammatory cells. In vitro studies use a great excess of dust, with many dust particles available for each cell to phagocytose. After dust inhalation, however, the dose each macrophage receives is likely to be considerably less owing to the filtration in the airways. Macrophages containing only a small amount of quartz may therefore survive for a long time before being killed or being activated to release chemoattractants. With chrysotile, however, many fibres will be incompletely phagocytosed causing chemoattractants and enzymes to be released more quickly, although in the long term the toxic effect may be less than with quartz.

In addition, the data from the macrophage spreading assay suggest that the activated macrophages produced by quartz and by chrysotile are phenotypically distinct, at least with regard to the membrane functions concerned with spreading on glass. Possibly the effector functions of the two macrophage populations are also different, and this may be expressed in the different kinetics of the inflammation produced by the two dusts and the different types of lesions found in quartz and in asbestos exposed lungs.

These results support the findings of several studies on human quartz and asbestos exposure. Macrophage and neutrophil alveolitis with increased lymphocytes was reported in asbestosis, ${ }^{34}$ similar to that described above. With quartz and coal dust containing quartz human bronchoalveolar lavage has shown a great increase in macrophages with only a modest increase in neutrophils. ${ }^{56}$ This is in contrast to our findings of large scale neutrophil recruitment as a result of quartz inhalation. This may be due to the higher dose used experimentally.

The kinetics of the bronchoalveolar leucocyte response to quartz and chrysotile asbestos delivered by inhalation exposure show important differences from those found with intratracheal instillation in previous studies. After intratracheal instillation of $5 \mathrm{mg}$ of silica into mice a rapid (within one week) increase occurred in lavage cell numbers, which plateaued throughout the remaining 12 weeks of the study. ${ }^{35}$ Silica $(2 \mathrm{mg})$ injected into mouse lungs caused a similar rapid rise in bronchoalveolar leucocytes; by eight weeks this had fallen to almost control levels but by 20 weeks, the end of the observation period, the response was increasing again..$^{36}$ Lugano et a ${ }^{37}$ described the cellular response after instillation of $50 \mathrm{mg}$ of silica into guinea pig lungs, where a sudden rise and decay in neutrophil response was followed by a slow rise in macrophage numbers up to 14 days after injection. Intratracheal instillation has also been used to study pulmonary responses to asbestos, where a very late onset alveolitis occurred 16 months after a cumulative dose of over $2 \mathrm{~g}$ of chrysotile by repeated instillation in sheep. ${ }^{38}$ Lemaire, ${ }^{7}$ using a single $5 \mathrm{mg}$ injection of chrysotile into rat lungs, obtained a maximal neutrophil response at one day followed by a decline in neutrophil numbers, which was replaced gradually by macrophage alveolitis. Similar treatment of hamsters ${ }^{39}$ resulted in an influx of neutrophils at day one, which remained at much the same level (about $20 \%$ ) 180 days after instillation.

The patterns of bronchoalveolar leucocyte response obtained in these studies with quartz and asbestos are complicated by differences in dose and species but are all very different from those described in the present study, where rats were exposed to respirable dust by inhalation. Because it is easy to use and relatively inexpensive, intratracheal instillation must continue to be a valuable tool for studying cellular responses within the lung to toxic agents, but its limitations are evident and have been studied. ${ }^{40}$ The particular course of the bronchopulmonary response obtained after inhalation exposure to respirable dust is clearly an important element in understanding the pathological outcome of exposure to any toxic dust.

\section{References}

1 Morgan WKC, Seaton A. Occupational lung diseases. Philadelphia: Saunders, 1984:323-76.

2 Gibbs AR, Seal RME, Wagner JC. Pathological reactions of the lung to dust. In: Morgan WKC, Seaton A, eds. Occupational Lung Diseases. Philadelphia: Saunders, 1984:129-62.

3 Gellert AR, Langford JA, Winter RJD, Uthayakumar S, Sinha G, Rudd RM. Asbestosis: assessment by bronchoalveolar lavage and measurement of pulmonary epithelial permeability. Thorax 1985;40:508-14.

4 Bignon J, Atassi K, Jaurand MC, Gesselin P, Solle R. Cellular and protein analysis of bronchoalveolar lavage fluid from patients with ideopathic pulmonary fibrosis and asbestosis. Am Rev Respir Dis 1978;117:56.

5 Voisin C, Wallaert B, Aerts C, Grosbois JM. Bronchoalveolar lavage in coalworkers' pneumoconiosis: oxidant and anti-oxidant activities of alveolar macrophages. In: Beck EG, Bignon J, eds. In vitro effects of mineral dusts. Berlin: Springer Verlag, 1985:93-100.

6 Voisin C, Gesselin B, Ramon PL, Wallaert B, Aerts C, Lenoir L. Le lavage broncho-alveolaire dans la pneumoconiose des mineurs de charbon. Aspects cytologiques. Rev Fr Mal Respir 1983;11:455-66.

7 Lemaire I. Characterisation of the bronchoalveolar cellular response in experimental asbestosis. Differing reactions depending on the fibrogenic potential. Am Rev Respir Dis 1985;131:1449. 
Kinetics of the bronchoalveolar leucocyte response in rats exposed to quartz, chrysotile, or titanium dioxide 533

8 Morgan A, Moores SR, Holmes A, Evans JC, Black A. The effect of quartz administered by intratracheal instillation, on the rat lung. I-The cellular response. Environ Res 1980;22:1-12.

9 Crystal RG, Gadek JE, Ferrans VJ, Fulmer JD, Line BR, Hunninghake GW. Interstitial lung disease. Current concepts of pathogenesis, staging and therapy. $\mathrm{Am} \mathrm{J}$ Med 1987;70:542-68.

10 Hunninghake GW, Gadek JE, Kawahami O, Ferrans J, Crystal RG. Inflammatory and immune processes in the human lung in health and disease. Evaluation by bronchoalveolar lavage. Am J Pathol 1979;97:149-206.

11 Richards RJ, White LR, Eik-Nes KB. Biological reactivity of different crystalline forms of titanium dioxide in vitro and in vivo. Scand $J$ Work Environ Health 1985;11:317-20.

12 Beckett ST. The generation and evaluation of UICC asbestos clouds in animal exposure chambers. Ann Occup Hyg 1975;18:187-98.

13 Wright BM. A new dust feed mechanism. J Sci Instrum 1950;27:12-6.

14 Timbrell V, Hyett AW, Skidmore JW. A simple dispenser for generating dust clouds from standard reference samples of asbestos. Ann Occup Hyg 1968;11:273-81.

15 Brain JD. The effects of increased particles in the number of alveolar macrophages. In: Walton $\mathrm{H}$, ed. Inhaled particles III. London: Unwin Bros, 1971.

16 Wroblewski F, Ladue JS. Lactic dehydrogenase activity in blood. Proc Soc Exp Biol Med 1953;90:210-3.

17 Woolen JW, Heyworth R, Walker PG. Studies on glucosaminidase 3. Testicular $N$-acetyl- $\beta$-glucosaminidase and the $N$-acetyl- $\beta$-galactosaminidase. Biochem $J$ 1961;78:111-6.

18 Donaldson K, Bolton RE, Brown D, Douglas A. An improved macrophage spreading assay a simple and effective measure of activation. Immunol Commun 1984;13:229-44.

19 Daum S, Anderson LA, Lilis R, et al. Pulmonary changes among titanium workers. Proc Norw Soc Med 1977;70:31-2.

20 Elo R, Maata K, Uksila E, Arstila AV. Pulmonary deposits of titanium dioxide in man. Arch Pathol 1972;94:417-24.

21 Ferin J, Oberdoster G. Biological effects and toxicity assessment of titanium dioxides, anatase and rutile. Am Ind Hyg Ass J 1985;46:69-72.

22 Lee KP, Trochimowicz HJ, Reinhardt CF. Pulmonary response of rats exposed to titanium dioxide $\left(\mathrm{TiO}_{2}\right)$ by inhalation for five years. Toxicol Appl Pharmacol 1985;79:179-92.

23 Donaldson K, Bolton RE, Brown D. Inflammatory cell recruitment as a measure of mineral dust toxicity. In: Dodgson J, McCallum RI, eds. Inhaled particles VI. Oxford: Pergamon Press (in press).

24 Bozelka BE, Sestini P, Gaumer R, Hammad Y, Heather $\mathrm{CJ}$, Salvaggio JE. A murine model of asbestosis. Am J Pathol 1983;112:326-37.

25 Kagan E, Oghiso Y, Hartmann D-P. The effects of chrysotile and crocidolite asbestos on the lower respiratory tract: analysis of bronchoalveolar lavage constituents. Environ Res 1983;32:382-97.

26 Miller K. The effects of asbestos on macrophages. CRC Crit Rev Toxicol 1978;5:319-54.

27 Davis JMG, Beckett ST, Bolton RE, Collings P, Middleton AP. Mass and number of fibres in the pathogenesis of asbestos-related lung disease in rats. Br J Cancer 1978;37:673-88.

28 Schoenberger CI, Hunninghake GW, Kawanami O, Ferrans HJ, Crystal RG. Role of alveolar macrophages in asbestosis: modulation of neutrophil migration to the lung after acute asbestos exposure. Thorax 1982;37:803-9.

29 Fantone JC, Ward P. Pathogenesis of the granulomatous lung diseases. Part III. Mechanisms of lung parenchymal injury. Am Rev Respir Dis 1984;130:484-91.

30 Lugano EM, Dauber JH, Daniele RP. Silica stimulation of chemotactic factor release by guinea pig alveolar macrophages. J Reticuloendothel Soc 1981;30:381-90.

31 Katsnelson BA, Privalova LI. Recruitment of phagocytosing cells into the respiratory tract as a response to the cytotoxic action of deposited particles. Environ Health Perspect 1984;55:313-25.

32 Le Bouffant L, Daniel H, Martin JC, Bruyere S. Effects of impurities and associated minerals on quartz toxicity. Ann Occup Hyg 1982;26:625-34.

33 Fogelmark B, Sjostrand M, Bergstrom R, Rylander R. Pulmonary macrophage phagocytosis and enzyme production after in vivo exposure to silica dust. Toxicol Appl Pharmacol 1983;68:152-9.

34 Harington J, Allison AC, Badami DV. Mineral fibres, chemical physiochemical and biological properties. Adv Pharmacol Chemotherapy 1975;12:291-402.

35 Callis AH, Sohnle PG, Mandel GS, Wiessner J, Mandel NS. Kinetics of inflammatory and fibrotic pulmonary changes in a murine model of silicosis. $\mathrm{J} \mathrm{Lab} \mathrm{Clin} \mathrm{Med}$ 1985;105:547-53.

36 Adamson IYR, Bowden DH. Role of polymorphonuclear leukocytes in silica-induced pulmonary fibrosis. Am J Pathol 1984;117:37-43.

37 Lugano EM, Dauber JH, Daniele RP. Acute experimental silicosis. Lung morphology, histology and macrophage chemotaxis secretion. Am J Pathol 1982;109:27-36.

38 Begin R, Rola-Pleszczynski M, Masse S, Nadeau D, Drapeau G. Assessment of progression of asbestosis in the sheep model by bronchoalveolar lavage and pulmonary function tests. Thorax 1983;38:449-57.

39 Glassroth JL, Bernards J, Lucey EC, Center DM, Jung-Legg $Y$, Snider GL. Interstitial pulmonary fibrosis induced in hamsters by intratracheally administered chrysotile asbestos. Am Rev Respir Dis 1984;130:242-8.

40 Pritchard JN, Holmes A, Evans JC, Evan N, Evans RJ, Morgan A. The distribution of dust in the rat lung following administration by inhalation and by single intratracheal instillation. Environ Res 1985;36:268-97. 